\title{
Comparação da reação de imunofluorescência indireta e do teste de aglutinação modificado na detecção de anticorpos anti-Toxoplasma gondii em ratos
}

\section{Comparison of the indirect fluorescent antibody test and modified agglutination test for detection of anti-Toxoplasma gondii antibodies in rats}

\author{
Gustavo Antonio Cola ${ }^{3}$; João Luis Garcia ${ }^{1}$; Letícia da Costa $^{2}$; Bruno Ruffolo ${ }^{2}$; \\ Italmar Teodorico Navarro ${ }^{1}$; Roberta Lemos Freire ${ }^{{ }^{*}}$
}

\section{Resumo}

\begin{abstract}
A toxoplasmose é uma zoonose causada pelo Toxoplasma gondii que acomete várias espécies carnívoras e onívoras, incluindo o ser humano. Os roedores são importantes na cadeia epidemiológica da doença por servirem de fonte de infecção aos felídeos, os hospedeiros definitivos deste protozoário. O objetivo deste trabalho foi avaliar o Teste de Aglutinação Modificada (MAT) na detecção de anticorpos contra T. gondii em ratos, comparando-o à Reação de Imunofluorescência Indireta (RIFI), considerada padrão ouro para o diagnóstico da toxoplasmose animal. Empregou-se o teste kappa para a comparação dos testes sorológicos (RIFI e MAT) e para a determinação do ponto de corte mais apropriado para a utilização do MAT, nesta espécie animal. Foram capturados 182 ratos em locais de reciclagem e armazenagem de resíduos sólidos na cidade de Londrina, PR. Destes, nove $(4,94 \%)$ foram positivos na RIFI na diluição 1:16; e 17 (9,34\%) e cinco (2,75\%) foram sororreagentes ao MAT nas diluições 1:25 e 1:50, respectivamente. A comparação dos resultados entre as técnicas apresentou coeficientes kappa de 0,26 e 0,55, respectivamente às diluições 1:25 e 1:50 do MAT. Conclui-se que a diluição 1:50 é a mais indicada para ser o ponto de corte na deteç̧ão de anticorpos contra $T$. gondii em ratos pelo MAT, por apresentar melhor concordância à RIFI.
\end{abstract}

Palavras-chave: Ratos. Toxoplasma gondii, anticorpos, diagnóstico sorológico, RIFI e MAT

\begin{abstract}
The toxoplasmosis is a zoonosis caused by Toxoplasma gondii and affects a lot of species of carnivores and omnivores, including the human. The rodents are important in the transmition cycle because they act as an infection font to felines, the definitive host of this protozoan. The objective of this work was to evaluate the Modified Agglutination Test (MAT) for the serologic diagnosis of toxoplasmosis in rats, comparing with the Indirect Fluorescent Antibody Test (IFAT), which has been considered the golden standard in animal toxoplasmosis diagnosis. Kappa test was used for comparing the serologic tests (IFAT and MAT) and for determination of cutoff appropriate to MAT in this animal species. 182 rats were caught on local recycling of solid waste and solid residue storage in Londrina city, Paraná. Out of
\end{abstract}

\footnotetext{
${ }^{1}$ Professor do Departamento de Medicina Veterinária Preventiva; Centro de Ciências Agrárias.Universidade Estadual de Londrina. E-mail: rlfreire@uel.br; jlgarcia@uel.br; italmar@uel.br

${ }^{2}$ Mestrando do Programa de Pós-graduação em Ciência Animal. Centro de Ciências Agrárias. Universidade Estadual de Londrina. E-mail: lelepaty2@yahoo.com.br; brunobergamo@ig.com.br

${ }^{3}$ Discente do Curso de Graduação em Medicina Veterinária. Centro de Ciências Agrárias. Universidade Estadual de Londrina e Bolsista de Iniciação Cientifica (PIBIC/CNPq). E-mail: gotha_@hotmail.com

* Autor para correspondência
} 
the 182 rats, nine $(4.94 \%)$ were positive to IFAT at a dilution of $1: 16$, and $17(9.34 \%)$ and five $(2.75 \%)$ were reactive to MAT in dilutions 1:25 and 1:50, respectively. The comparison of results between the techniques presented kappa coefficients of 0.26 and 0.55 , respectively at 1:25 and 1:50 dilutions of MAT. It can be concluded that the dilution 1:50 is the most suitable to be used as cutoff for detecting $T$. gondii antibodies in rats using MAT, because agreed with IFAT.

Key words: Rat. Toxoplasma gondii. Antibodies. Serologic diagnosis. IFAT and MAT.

\section{Introdução}

Os ratos são espécies com grande capacidade de adaptação ao meio ambiente, principalmente naquele em que o homem habita, devido às condições básicas que estes lugares proporcionam como: alimento, água e abrigo. Tais fatores levam ao aumento destes animais nas áreas urbanas, tornando mais frequente as doenças por eles transmitidas.

A toxoplasmose é causada pelo Toxoplasma gondii, um protozoário que acomete varias espécies homeotérmicas, inclusive o ser humano. Os roedores se infectam em sua maior parte, pela ingestão de oocistos esporulados no solo ou por via transplacentária, que corresponde a menos de 1\% dos casos em ratos (DUBEY; FRENKEL, 1998). Ratos infectados são importantes na cadeia epidemiológica da toxoplasmose e servem como fonte de infecção para carnívoros e onívoros, principalmente os felídeos (gato doméstico) que são os hospedeiros definitivos. Segundo Webster (2001), ratos infectados pelo T. gondii ficam menos cautelosos e diminuem sua habilidade de fuga, além de serem atraídos pelo odor da urina do seu predador, tornando-os presas fáceis aos gatos.

A técnica comumente utilizada para a detecção de anticorpos anti- $T$. gondii, nas diferentes espécies animais, é a Reação de Imunofluorescência Indireta (RIFI) (VIDOTTO et al., 1990; GARCIA et al., 1999), porém requer reagentes espéçie-específicos, microscópio para fluorescência e treinamento técnico para a leitura das lâmnias. O Teste de Aglutinação Modificada (MAT), segundo o método proposto por Desmonts e Remington (1980), é um teste macroscópico que está sendo amplamente utilizado e validado para diferentes espécies animais (SILVA; CUTOLO; LANGONI, 2002), devido a facilidade de realização e concordância aos outros testes de diagnóstico.

O objetivo deste trabalho foi avaliar o MAT, em diferentes pontos de corte, para a detecção de anticorpos contra $T$. gondii em ratos, comparando-o à RIFI que é considerada padrão ouro no diagnóstico da toxoplasmose murina.

\section{Material e Métodos}

\section{Local de coleta e amostragem}

Os pontos de coleta de dados e animais foram os locais de reciclagem e ferros-velhos existentes nas cinco regiões da cidade de Londrina, PR (Norte, Sul, Leste, Oeste e Central). O número de roedores capturados foi calculado utilizando o programa EPIINFO (DEAN et al., 1994). Para uma população infinita, com prevalência estimada de $50 \%$, precisão de 7,5\% e nível de significância de 5\%, determinouse a amostra composta por 171 ratos. O trabalho foi registrado ( ${ }^{\circ}$ 28/06) e aprovado pelo Comitê de Ética em Experimentação Animal da Universidade Estadual de Londrina, PR.

\section{Capturas dos roedores}

Os ratos foram capturados utilizando-se armadilhas do tipo gaiola, nas quais o mecanismo de disparo é acionado por uma isca colocada em seu interior. As armadilhas foram montadas ao final da tarde em locais com indícios de passagem de roedores, como: fezes, manchas de gorduras e trilhas, ou em lugares com grande oferta de alimentos, e vistoriadas na manhã do dia seguinte. 


\section{Sorologia}

Reação de imunofluorescência indireta (RIFI):

Os soros dos ratos capturados foram submetidos à pesquisa de anticorpos da classe IgG anti-T. gondii (CAMARGO, 1973). Utilizou-se como antígeno taquizoítas da cepa RH. Foram utilizados conjugados marcados com isotiocianato de fluoresceína, específico para as espécies murinas (SIGMA CHEMICAL CO. E ZIMED) e soros controle positivos e negativos. Considerou-se positivas as diluições $\geq 1: 16$ (NAVARRO et al., 1992; DUBEY; FRENKEL, 1998).

Teste aglutinação modificada (MAT)

Os soros dos ratos foram submetidos à pesquisa de anticorpos da classe IgG anti-T.gondii segundo Desmonts e Remington (1980). As amostras foram triadas nas diluições 1:25 e 1:50 em microplacas com 96 poços de fundo chato (Corning $\AA)$. Foram consideradas reagentes as diluições que formaram uma película ou malha em pelo menos $50 \%$ do fundo da cavidade da microplaca e não reagentes as diluições que formaram um botão compacto ou ocupando até $50 \%$ do fundo da cavidade. Em todas as microplacas foram testados soros controle positivo e negativo para auxílio à interpretação dos resultados.

\section{Análise estatística}

Foi calculado o índice kappa para avaliar a associação entre os resultados obtidos com a RIFI e o MAT e, com base neste, determinar o ponto de corte adequado para a utilização do MAT na detecção de anticorpos contra $T$. gondii em soros murinos (COHEN, 1960).

Para uma interpretação dos valores de kappa, utilizou-se a caracterização em faixas de valores segundo Landis e Koch (1977). Esses autores sugerem que os valores de 0,01 a 0,2 representam concordância pequena, de 0,21 a 0,4 uma concordância média, de 0,41 a 0,6 moderada, de 0,61 a 0,8 substancial e de 0,81 a 1,0 representariam concordância excelente.

\section{Resultados}

Foram capturados 182 roedores em 37 locais de armazenamento e reciclagem de resíduos sólidos na cidade de Londrina. Dos roedores capturados, 181 $(99,4 \%)$ pertenciam à espécie Rattus rattus e um $(0,6 \%)$ à espécie Mus musculus, sendo 77 (42,3\%) machos e 105 (57,7\%) fêmeas.

$\mathrm{Na}$ RIFI nove $(4,94 \%)$ ratos foram positivos e ao MAT houve 17 (9,34\%) sororreagentes à diluição $1: 25$ e cinco $(2,75 \%)$ à diluição $1: 50$. Obtiveram-se índices kappa de 0,26 e 0,55 quando comparados os resultados da detecção de anticorpos contra $T$. gondii pelo MAT, nas respectivas diluições de 1:25 e 1:50, e pela RIFI. Houve melhora na especificidade do MAT e, consequentemente, na validade dos resultados positivos quando empregada a diluição 1:50, (Tabela 1). 
Tabela 1. Comparação dos resultados das técnicas de RIFI e MAT dos títulos dos anticorpos de anti-Toxoplasma gondii em soros de ratos capturados na cidade de Londrina PR, 2006.

\begin{tabular}{|c|c|c|c|c|}
\hline & RIFI + & RIFI - & Total & \\
\hline MAT + & 04 & 13 & 17 & \\
\hline MAT - & 05 & 160 & 165 & \\
\hline Total & 09 & 173 & 182 & kappa $=0,26$ \\
\hline
\end{tabular}

$\begin{array}{lrl}\text { A }- \text { MAT na diluição 1:25 } & & \\ \text { Sensibilidade } & 44,4 \% & \text { (IC 95\%: } 15,3-77,3) \\ \text { Especificidade } & 92,5 \% & \text { (IC 95\%: 87,2-95,8) } \\ \text { Valor Preditivo Positivo } & 23,5 \% & \text { (IC 95\%: 7,8 - 50,2) } \\ \text { Valor Preditivo Negativo } & 97,0 \% & \text { (IC 95\%: } 92,7-98,9)\end{array}$

\begin{tabular}{ccccc}
\hline & RIFI + & RIFI - & Total & \\
\hline BAT + & 04 & 01 & $\mathbf{0 5}$ & \\
MAT - & 05 & 172 & $\mathbf{1 7 7}$ & \\
\hline Total & $\mathbf{0 9}$ & $\mathbf{1 7 3}$ & $\mathbf{1 8 2}$ & kappa $=\mathbf{0 , 5 5}$ \\
\hline
\end{tabular}

B - MAT na diluição 1:50

Sensibilidade

Especificidade

Valor Preditivo Positivo

Valor Preditivo Negativo
44,4\% (IC 95\%: 15,3-77,3)

99,4\% (IC 95\%: 96,3-100,0)

$80,0 \%$ (IC 95\%: 29,9-98,9)

97,2\% (IC 95\%: 93,2-99,0)

\section{Discussão e Conclusão}

No presente estudo nove $(4,94 \%)$ ratos foram positivos na RIFI, ao MAT dezessete $(9,34 \%)$ foram reagentes à diluição $1: 25$ e cinco $(2,75 \%)$ à diluição 1:50. Dubey et al. (2006) constataram uma prevalência de $0,9 \%$ utilizando o MAT com ponto de corte de 1:40, em 238 ratos da espécie $R$. norvegicus na ilha de Grenada, West Indies, Caribe. Yai (2007) estudou 68 capivaras do estado de São Paulo e encontrou uma soroprevalência de $75 \%$ utilizando o MAT e o ponto de corte na diluição 1:25. Em um trabalho realizado no México, Dubey et al. (2009) encontraram uma prevalência de ratos infectados de $0,8 \%(2 / 249)$ e de $3,1 \%(4 / 127)$ de camundongos, utilizando o MAT na diluição 1:25. Em Israel, Salant et al. (2009) obtiveram uma prevalência em torno de $84 \%(21 / 25)$ para um titulo de $1: 16$ e $8 \%(2 / 25)$ para um título de 1:32 no MAT. Estes dados demonstram que a escolha da diluição a ser utilizada como ponto de corte no MAT deve levar em consideração a

concordância aos testes considerados padrão ouro e a melhoria da validade dos resultados.

No Brasil, Silva, Cutolo e Langoni (2002) examinaram 100 soros de cada espécieovina, caprina, canina e felina e compararam a RIFI e o MAT, em ambos os testes foram adotadas as diluições de $1: 16,1: 64$ e 1:256. Os resultados apresentaram coeficiente kappa entre 0,59 a 0,84, indicando concordância entre os dois métodos. Franco et al. (2003) avaliando uma amostra de 157 soros de cães do município de Monte Negro, RO, observaram $76,40 \%$ de animais positivos ao $T$. gondii pela RIFI (1:16) e, quando comparado com o MAT (1:25), verificaram sensibilidade de $85 \%$ e especificidade de $100 \%$. Minho et al. (2004) compararam a RIFI e MAT em suínos experimentalmente infectados e obtiveram sensibilidade e especificidade semelhantes utilizando como ponto de corte na RIFI 1:16 e no MAT 1:25, o cálculo de kappa resultou no índice 0,93 considerado excelente. . Em um estudo 
realizado em suínos da região oeste do Paraná por Silva et al (2008), foram encontrados 7,2\% de animais positivos, através do MAT.

Em um estudo comparativo de sensibilidade e especificidade com vários testes sorológicos para a detecção de anticorpos contra $T$. gondii, conduzido em 1000 porcas naturalmente infectadas e utilizando como teste padrão ouro o isolamento de parasitas viáveis, o MAT foi o mais especifico e sensível para o diagnostico de toxoplasmose crônica. (DUBEY et al., 1995). Segundo Marca et al. (1996) e Franco et al. (2003), o MAT apresenta alta sensibilidade e especificidade na detecção de anticorpos anti- $T$. gondii quando comparado a outras técnicas. Com o ponto de corte 1:100 no MAT, Klun et al. (2007) obtiveram uma concordância de kappa moderada, quando comparada ao ELISA, em um estudo realizado em ovinos naturalmente infectados pelo T. gondii. Como verificado em vários trabalhos com diferentes espécies animais, o MAT resulta num maior numero de resultados positivos e títulos ligeiramente mais altos quando comparados com a RIFI (SILVA; CUTOLO; LANGONI, 2002) e, como aponta Dubey et al. (1985), este resultado deve estar relacionado aos diferentes subtipos de IgG detectados em cada teste sorológico.

Seefeldt et al. (1989) citam o MAT como prova de escolha frente ao ELISA e à RIFI para o diagnóstico de anticorpos anti- $T$. gondii em ovinos. Entre as principais vantagens do método estão a praticidade, a viabilidade para testar pequeno número de amostras, a facilidade de leitura sem necessidade de instrumentos especiais, a possibilidade de realização do teste para qualquer espécie animal e a de se testar amostras recentemente autolisadas, diferentemente do que ocorre com a RIFI.

No presente estudo, mesmo que a concordância de kappa seja moderada, o ponto de corte na diluição 1:50 foi o mais indicado para utilização do MAT no diagnóstico de toxoplasmose em ratos, pois melhorou a especificidade do teste e a validade dos resultados positivos, diminuindo o número de falsos positivos.

\section{Agradecimentos}

Os autores agradecem à Pro Reitoria de PósGraduação da Universidade Estadual de Londrina, pela concessão das bolsas de Iniciação Científica para os acadêmicos de Medicina Veterinária; à Fundação Araucária de Apoio ao Desenvolvimento Científico e Tecnológico do Paraná pelo suporte financeiro (Convênio302/2007, protocolo 4851).

\section{Referências}

CAMARGO, M. E. Introdução às técnicas de imunofluorescência. Revista Brasileira de Patologia Clínica, Rio de Janeiro, v. 10, n. 4, p. 143-171, 1973.

COHEN, J. A coefficient of agreement for nominal scale. Educational and Psychological Measurement, USA, v. 20, n. 1, p. 37-46, 1960.

DEAN, A. G.; DEAN, J. A.; COULOMBIER, D.; BRENDEL, K. A.; SMITH, D. C.; BURTON, A. H.; DICKER, R. C.; SULLIVAN, K.; FAGAN, R. F.; ARNER, T. G. Epi info, version 6: a word processing, database, and statistics program for public health on IBM-compatible microcomputers. Centers for Disease Control and Prevention, Atlanta, Georgia, U.S.A., 1994.

DESMONTS, G.; REMINGTON, J. Direct agglutination test for diagnosis of Toxoplasma infection: method for increasing sensitivity and specificity. Journal of Clinical Microbiology, USA, v. 11, n. 6, p. 562-568, 1980.

DUBEY, J. P.; VELMURUGAN, G. V.; ALVARADOESQUIVEL, C.; ALVARADO-ESQUIVEL, D.; RODRÍGUEZ-PEÑA, S.; MARTÍNEZ-GARCÍA, S.; GONZÁLEZ-HERRERA, A.; FERREIRA, L. R.; KWOK, O. C. H.; SU, C. Isolation of Toxoplasma gondii from Animals in Durango, Mexico. Journal of Parasitology, USA, v. 95, n. 2, p. 319-322, 2009.

DUBEY, J. P.; BHAIYAT, M. I.; MACPHERSON, C. L.; ALLIE, C.; CHIKWETO, A.; KWOK, O. C.; SHARMA, R. N. Prevalence of Toxoplasma gondii in rats (Rattus norvegicus) in Grenada, West Indies. Journal of Parasitology, USA, v. 92, n. 5, p. 1107-1108, 2006.

DUBEY, J. P.; DESMONTS, G.; ANTUNES, F.; MCDONALD, C. Serologic diagnosis of toxoplasmosis experimentallyinfectedpregnantgoatsandtransplacentally infected kids. American Journal Veterinary Research, USA, v. 46, n. 5, p. 1137-1140, 1985.

DUBEY, J. P.; FRENKEL, J. K. Toxoplasmosis of rats: a review, with considerations of their value as an animal 
model and their possible role in epidemiology. Veterinary Parasitology, USA, v. 77, n. 1, p. 1-32, 1998.

DUBEY, J. P.; THULLIEZ, P.; WEIGEL, R. M.; ANDREWS, C. D.; LINF, P.; POWELL, E. C. Sensitivity and specifity of various serologic tests for detection of Toxoplasma gondii infection in naturally infected sows. American Journal Veterinary Research, USA, v. 56, n. 8, p. 1030-1036, 1995.

FRANCO, W. A. C.; BERGAMASCHI, D. P.; RICHTZENHAIN, L. J.; NOQUEIRA, Y.; CAMARGO, L. M. A.; SOLSA S, L. P.; GENNARI, S. M. Evaluation of the performance of the modified direct agglutination test (MAT) for detection of Toxoplasma gondii antibodies in dogs. Brazilian Journal Veterinary Research Animal Science, São Paulo, v. 40, n. 6, p. 452-456, 2003.

GARCIA, J. L.; NAVARRO, I. T.; OGAWA, L.; OLIVEIRA, R. C. Soroepidemiologia da toxoplasmose em gatos e cães de propriedades rurais do Município de Jaguapitã, Estado do Paraná, Brasil. Ciência Rural, Santa Maria, v. 29, n. 1 , p. 99-104, 1999.

KLUN, I.; DJURKOVIC-DJAKOVIC, O.; THULLIEZ, P. Comparison of a commercial ELISA with the modified agglutination test for the detection of Toxoplasma gondii infection in naturally exposed sheep. Zoonoses Public Health, Washington, v. 54, n. 3/4, p. 165-168, 2007.

LANDIS, J. R.; KOCH, G. G. The measurement of observer agreement for categorical data. Biometrics, Arlington, v. 33, n. 1, p. 159-174, 1977.

MARCA, M. C.; RAMOS, J. J.; LOSTE, A.; SAEZ, T.; SANZ, M. C. Comparison of indirect immunofluorescent antibody test and modified direct agglutination test methods for detection of Toxoplasma gondii antibodies in adult sheep in Spain. Veterinary Parasitology, USA, v. 67, n. 1/2, p. 99-103, 1996.

MINHO, A. P.; FREIRE, R. L.; VIDOTTO, O.; GENNARI, S. M.; MARANA, E. R. M.; GARCIA, J. L.; NAVARRO, I. T. Evaluation of the indirect fluorescent antibody test and modified agglutination test for detection of antibodies against Toxoplasma gondii in experimentally infected pigs. Pesquisa Veterinária Brasileira, Rio de Janeiro, v. 24, n. 4, p. 199-202. 2004.
NAVARRO, I. T.; VIDOTTO, O.; GIRALDI, N.; FREIRE, R. L. Toxoplasma gondii: isolamento a partir de carne e cérebro de suínos comercializados na região de Londrina, Pr. Semina: Ciências Agrárias, Londrina, v. 13, n. 1, p. 15-18, 1992.

SALANT, H.; WEINGRAM, T.; SPIRA, D. T.; EIZENBERG, T. An outbreak of Toxoplasmosis amongst squirrel monkeys in an Israeli monkey colony. Veterinary Parasitology, USA, v. 159, n. 1, p. 24-29, 2009.

SEEFELDT, S. L.; KIRKBRIDE, C. A.; DUBEY, J. P. Comparison of enzyme-linked immunosorbent assay, indirect fluorescent antibody test, and direct agglutination test for detecting Toxoplasma gondii antibodies in naturally aborted ovine fetuses. Journal Veterinary Diagnostic Investigation, Davis, v. 1, n. 2, p. 124-127, 1989.

SILVA, A.; BOARETO, H.; ISBRECHT, F. B.; SILVA, R. C.; LANGONI, H. Ocorrência de anticorpos antiToxoplasma gondii em suínos da região Oeste do Paraná, Brasil. Veterinária e Zootecnia, Botucatu, v. 15, n. 2, p. 263-266, 2008

SILVA, A. V.; CUTOLO, A. A.; LANGONI, H. Comparação da reação de imunofluorescência indireta $\mathrm{e}$ do método de aglutinação direta na detecção de anticorpos anti-Toxoplasma em soros de ovinos, caprinos, caninos e felinos. Arquivos do Instituto Biológico, São Paulo, v. 69, n. 1, p. 7-11, 2002.

VIDOTTO, O.; NAVARRO, I. T.; GIRALDI, N.; MITSUKA, R.; FREIRE, R. L. Estudos epidemiológicos da toxoplasmose em suínos da Região de Londrina- Pr. Semina: Ciências Agrárias, Londrina, v. 11, n. 1, p. 5359, 1990.

WEBSTER, J. P. Rats, cats, people and parasites: the impact of latent toxoplasmosis on behaviour. Microbes and Infection, Paris, v. 3, n. 12, p. 1037-1045, 2001.

YAI, L. E .O. Caracterização biológica e genotipagem de isolados de Toxoplasma gondii de capivara (Hydrochaeris hydrochaeris) do Estado de São Paulo. 2007. Tese (Doutorado) - Universidade de São Paulo. Faculdade de Medicina Veterinária e Zootecnia. Departamento de Medicina Veterinária Preventiva e Saúde Animal, São Paulo. 